\title{
3D Printing Magnesium-Doped Wollastonite/ $\beta$-TCP Bioceramics Scaffolds with High Strength and Adjustable Degradation
}

\author{
Huifeng Shao ${ }^{1,2}$, Yong $\mathrm{He}^{1,2}$, Jianzhong $\mathrm{Fu}^{1,2}$, Dongshuang $\mathrm{He}^{3}$, Xianyan Yang ${ }^{3}$, Jiajun Xie ${ }^{4}$, Chunlei Yao ${ }^{4}$, \\ Juan Ye ${ }^{4}$, Sanzhong $\mathrm{Xu}^{5}$, and Zhongru Gou* ${ }^{3 *}$ \\ ${ }^{1}$ State Key Laboratory of Fluid Power and Mechatronic Systems, College of Mechanical Engineering, Zhejiang \\ University, Hangzhou 310027, China.
}

${ }^{2}$ Key Laboratory of 3D Printing Process and Equipment of Zhejiang Province, College of Mechanical Engineering, Zhejiang University, Hangzhou 310027, China.

${ }^{3}$ Zhejiang-California International Nanosystem Institute, Zhejiang University, Hangzhou 310058, China.

${ }^{4}$ Zhejiang Provincial Key Lab of Ophthalmology, Second Affiliated Hospital, School of Medicine of Zhejiang University, Hangzhou 310009, China.

${ }^{5}$ Department of Orthopedics, The First Affiliated Hospital, School of Medicine of Zhejiang University, Hangzhou 310003, China.

\footnotetext{
*Corresponding author

Yong He, Ph.D.

College of Mechanical Engineering

Zhejiang University, Hangzhou 310027, China

E-mail: yongqin@zju.edu.cn

Zhongru Gou, Ph.D.

Zhejiang-California International Nanosystems Institute

Zhejiang University, Hangzhou 310029, China

Tel: (+86) 571-8697 1782

Fax: (+86) 571-8697 1539

E-mail: zhrgou@zju.edu.cn
} 


\begin{abstract}
Mechanical strength of bioceramic scaffolds is a problem to treat the load bearing bone defects. We developed the Mg-doping wollastonite (CSi-Mg)-based scaffolds with high strength via 3D printing technology. The effect of pore size, $\beta$-tricalcium phosphate $(\beta$-TCP) content $(x \%)$, and heating schedule on the strength of scaffolds were investigated systematically. Incorporation of $\beta$-TCP could readily adjust the sintering properties of the $\mathrm{CSi}-\mathrm{Mg}$ scaffolds and the scaffolds with high (20 30\%) and low (10 20\%) $\beta$-TCP possess much high strength (80 100 MPa or $120 \sim 140 \mathrm{MPa})$ after undergoing one- or two-step sintering. Meanwhile, the CSi-Mg/TCP $x(x=10,20)$ with medium-pore $(\sim 320 \mu \mathrm{m})$ had over $100 \mathrm{MPa}$ in compression and $\sim 52 \%$ in porosity. In particular, the composite scaffolds maintained appreciable strength (over $50 \mathrm{MPa}$ ) after immersion in Tris buffer for a long time stage (6 weeks). These findings demonstrate that the CSi-Mg/TCP $x$ scaffolds are promising for treating some challengeable bone defects, especially for load-bearing bone repair.
\end{abstract}

Keywords: Bioceramic scaffolds; Mg-doping wollastonite; Tricalcium phosphate; Mechanical properties; 3D printing.

\title{
1. Introduction
}

Large load-bearing bone defects following trauma, infection, or tumor excision remain a major healthcare issue for reconstructive surgeons because of the difficulties in reconstructing large bone segments [1-3]. Segmental bone is usually exposed to compression, tension, and shear associated with normal body movement. Material-based approaches that yield tissue-engineered substitutes offer compelling alternatives in the treatment of the large bone damages [4-6]. However, the challenge in the field of porous scaffolds is developing one that matches the biomechanical properties of bone and also has sufficient bioactivity to stimulate new bone regeneration $[7,8]$.

Driven by the demand for efficient and full repair of bone defects, bioactive ceramic and its composites are advancing toward to high mechanical strength, good bioactivity, and controlled biodegradation, and this trend is poised to be accelerated with the replacement of Ca-phosphate ceramics by Ca-silicate ceramics in the near future. Wollastonite $\left(\mathrm{CaSiO}_{3} ; \mathrm{CSi}\right)$ is a promising bone implants due to its good osteoconductivity and bioresorbability, which has been either studied as alloy coating, granules or a sintered porous body with defined shape [9,10]. Most recently, we found that the CSi ceramic can be rationally tuned in phase ( $\alpha$ or $\beta$ ), mechanical strength (in 
compression and bending mode), and fracture toughness $\left(>3.2 \mathrm{MPa} \cdot \mathrm{m}^{1 / 2}\right)$ through the usage of $\mathrm{Mg}$ doping at precisely defined dilute contents [11]. The optimal mechanical parameters, which match well with the load-bearing bone conditions, can be obtained when 6-10 mol\% $\mathrm{Ca}$ is substituted by $\mathrm{Mg}$ in CSi. In this regard, such new dilute $\mathrm{Mg}$ doping calcium silicate ( $\mathrm{CSi}-\mathrm{Mg}$ ) ceramic will be promising for making specific porous scaffolds for enhancing large-area segmental bone defect regeneration and repair in situ.

On the other hand, the production of anatomically correct surgical models has paved the way for the development of scaffolds designed to patient-specific geometries. Additive manufacturing technologies (AMTs) have been at the forefront of fabricating porous materials, which allows the production of porous scaffolds with complex geometries containing internal pore architectures. Ceramic ink writing (extrusion-based 3D printing) is one of these AMTs and works through pre-mixing organic binder to consolidate ceramic inks into a 3D porous architecture with designed shape, controlled chemistry and interconnected porosity [12-15]. Fu et al. used ceramic ink writing and one-step sintering post-treatment to produce high-strength bioactive glass scaffolds [16] and some 3D printed bioceramic scaffolds have been used for treatment of patients with severely atrophic posterior mandibles or critical sized complex cranial defects in rabbits [17]. Nevertheless, the high binder content in ceramic ink usually result in low densification in pore strut after sintering, which is specially disadvantageous for the mechanical strength of bioceramic scaffolds. Accordingly, the mechanical reliability problem caused by ceramic ink writing becomes a bottleneck hindering the advancement of such porous bioceramic scaffold technology.

Herein, we hypothesized that the addition of $\beta$-TCP is convenient to tailor the bioresorbability of CSi-Mg-based porous ceramics. In fact, it has been demonstrated in animal models that the degradation rate of $\beta$-TCP porous scaffolds is slower than the bone regeneration rate, but in contrast, the pure CSi porous ceramic shows overfast biodegradation in vivo [18]. Accordingly, the fabrication of the CSi-Mg/TCP composite scaffolds using ceramic ink writing technology can be used potentially in large segmental bone defect treatment. In the present study, a detailed investigation of the composition-structure-strength relationship during one- or two-step sintering has been performed to explore the main function refinement in extrusion-based 3D printing porous bioceramics.

\section{Materials and methods}

\subsection{Synthesis of CSi-Mg powders and TCP powders}


The CSi-Mg powder containing $2.12 \mathrm{wt} \% \mathrm{Mg}(10 \mathrm{~mol} \% \mathrm{Ca}$ was substituted by $\mathrm{Mg}$ in wollastonite) were synthesized by a conventional wet-chemical co-precipitation method [11]. The as-calcined CSi-Mg powders were ground using zirconia ball media in ethanol for $4 \mathrm{~h}$. The particle size of the resulting powders was below $2 \mu \mathrm{m}$. The $\beta$-TCP powders were synthesized by a co-precipitation method and were also ground for $4 \mathrm{~h}$.

\subsection{Ceramic ink writing of CSi-Mg/TCP scaffolds}

The CSi-Mg/TCP $x$ powders with different $\beta$-TCP content ( $x$ wt $\%$ ) from $0 \%$ to $30 \%$ were mechanically mixed by ball milling in $100 \%$ ethanol for $30 \mathrm{~min}$, and then dried at $90^{\circ} \mathrm{C}$ overnight. Then the CSi- $\mathrm{Mg} / \mathrm{TCP} x$ paste for layerby-layer printing of the composite scaffolds was optimally prepared by mixing $5.4 \mathrm{~g}$ of composite powders with 4.0 g of $6.0 \%$ polyvinyl alcohol (PVA, Sigma-Aldrich) solution. Thus, the CSi-Mg/TCP $x$ scaffolds with square pore morphology of $0^{\circ} / 90^{\circ}$ strut structure were prepared by using our home-made $3 \mathrm{D}$ printing equipment. The pure $\beta$-TCP scaffolds were prepared by the same method as control. After that, the samples were dried at $80^{\circ} \mathrm{C}$ overnight before sintering. To investigate the effect of porosity of ceramic scaffolds on the mechanical strength, the small-pore $(220 \times 220 \mu \mathrm{m})$, medium-pore $(320 \times 320 \mu \mathrm{m})$, and large-pore $(480 \times 480 \mu \mathrm{m})$ scaffolds were fabricated while the other conditions remained the same.

\subsection{Scaffolds sintering}

In order to evaluate the effect of sintering process on mechanical properties, two main sintering routes were conducted including one-step sintering (OSS) and two-step sintering (TSS) methods. OSS was performed by sintering in a furnace at a target temperature, $T\left(1120^{\circ} \mathrm{C}, 1150^{\circ} \mathrm{C}\right.$, or $\left.1180^{\circ} \mathrm{C}\right)$ for $3 \mathrm{~h}$ in air atmosphere using similar heating schemes, with heating rate of $3^{\circ} \mathrm{C} / \mathrm{min}$, and followed by cooling naturally. TSS was carried out in three heating regimes. Samples were fired up to the higher target temperature $\left(T_{1}=1120^{\circ} \mathrm{C}, 1150^{\circ} \mathrm{C}\right.$, or $\left.1180^{\circ} \mathrm{C}\right)$, with heating rate of $3^{\circ} \mathrm{C} / \mathrm{min}$ and held at $T_{1}$ for two time lengths ( $t=45 \mathrm{~min}$ or $15 \mathrm{~min}$ ), then rapidly cooled down to the lower target temperature $\left(T_{2}=1060^{\circ} \mathrm{C}\right)$, within in $10 \mathrm{~min}$ and finally held at $T_{2}$ for $3 \mathrm{~h}$.

\subsection{Physicochemical characterization of the powders and scaffolds}

The scaffolds sintered at $1180^{\circ} \mathrm{C}$ were verified by X-ray diffractometer (XRD; Rigaku D/max-rA) at $40 \mathrm{kV} / 40 \mathrm{~mA}$. Data were collected with a step of $0.02^{\circ} / 2 \theta$ and a dwell time of $1.5 \mathrm{~s}$ to identify crystalline phase of the powders. In order to investigate the size distribution of particles, dynamic light scattering (DLS, Malven Instrument 2000) was 
used. The scaffold morphology and pore structure were observed by optical microscopy (Olympus). Scanning electron microscopy (SEM; JEM-6700F) was used to observe the Au-coated surface and fracture surface of the scaffolds at an accelerating voltage of $10 \mathrm{kV}$. The $\mu \mathrm{CT}$ analysis (SkyScan), a powerful non-destructive testing method, was employed to characterize the porosity, pores interconnectivity, and $2 \mathrm{D}, 3 \mathrm{D}$ constructs of the sintered scaffolds. The open porosity of the scaffolds $(n=6)$ was also measured using a mercury porosimetry (AutoPore IV 9510). $\mathrm{Hg}$ intrusion volume during the high pressure loading phase was determined in $\mathrm{cm}^{3}$ per unit sample weight.

\subsection{Mechanical testing}

Rectangular scaffolds $(n=6 ; 7 \mathrm{~mm} \times 7 \mathrm{~mm} \times 10 \mathrm{~mm})$ were prepared for compressive strength and elastic modulus measurement. Mechanical testing was performed using a static mechanical test machine (Instron 5566) and a $10 \mathrm{kN}$ load cell, and samples were tested at a constant cross head displacement rate of $0.5 \mathrm{~mm} / \mathrm{min}$. The elastic modulus was determined from the linear region of the stress vs. strain response.

\subsection{Degradation and mechanical stability evaluation in vitro}

For evaluation of degradation (biodissolution), Tris buffer with an initial $\mathrm{pH} 7.4$ for 2, 4, and 6 weeks, respectively, and a S/L ratio of $1.0 \mathrm{~g} / 200 \mathrm{ml}$ was used. After immersing for every $24 \mathrm{~h}, 0.5 \mathrm{ml}$ of supernatant was extracted for inductively coupled plasma (ICP; Thermo) measurement. An equal volume of fresh buffer was added to keep volume constant, and then 20 vol\% solution was refreshed with fresh buffer every $3 \mathrm{~d}$. At the pre-set time stage, the scaffolds were rinsed with ethanol and then dried at $100^{\circ} \mathrm{C}$ for $12 \mathrm{~h}$, and weighed $\left(\mathrm{W}_{\mathrm{t}}\right)$. The weight at time $t$ was expressed as: Weight $=\mathrm{W}_{\mathrm{t}} / \mathrm{W}_{0} \times 100 \%$. The $\mathrm{pH}$ value in the medium was measured by $\mathrm{pH}$ meter. The mechanical strength of the asdried scaffolds was also determined by Instron testing machine.

\subsection{Statistical analysis}

All the data above were expressed as mean \pm standard deviation (SD) and analyzed with the one-way ANOVA. In all cases the results were considered statistically significant with a $p$-value less than 0.05 .

\section{Results and discussion}

\subsection{Primary characterization of the 3D printed scaffolds}

According to the SEM observation, the as-milled CSi-Mg and $\beta$-TCP powders were both comprised of superfine particles with below $2 \mu \mathrm{m}$ in size (Fig. S1; see Supporting Information (SI)). The CSi-Mg/TCP $x$ scaffolds were then 
fabricated as described in our previous work [19], and the representative ink formulations were provided in the Table 1. The linear shrinkage of the CSi-Mg/TCP $x$ scaffolds was mildly reduced with increasing TCP content (Tab. S1, SI).

Figure 1A shows the optical images of the typical scaffolds with defined filament diameter and pore morphology patterned by the 3D printer. Nearly square pores were observed throughout the whole vertical direction and the horizontal side pores with rectangular morphology could be easily observed after sintering. In addition, as shown in Figure $1 \mathrm{~B}$, the internal $2 \mathrm{D}$ and $3 \mathrm{D}$ visualizations of the $\mathrm{CSi}-\mathrm{Mg} / \mathrm{TCP} x$ porous bioceramics with fully interconnected pore structure could be confirmed by $\mu \mathrm{CT}$ analysis. XRD patterns of the $\mathrm{CSi}-\mathrm{Mg} / \mathrm{TCP} x$ scaffolds sintered at $1180^{\circ} \mathrm{C}$ for $3 \mathrm{~h}$ (Fig. 1C) indicated that the bioceramic scaffolds were all the composites of wollastonite-2M (PDF\# 27-0088) and $\beta$-TCP (PDF \#09-0169), suggesting no secondary chemical reaction during sintering. As we know, additionally, pure CSi mainly exists in two polymorphs, namely $\beta$-CSi and $\alpha$-CSi, which are generally regarded as low- and hightemperature crystal forms, respectively. During sintering, pure CSi raw powder, which is usually $\beta$ phase, converts to the more stable $\alpha$ phase when increasing the temperature up to $1120^{\circ} \mathrm{C}$ [20]. However, the XRD analysis in this study demonstrated that the $\beta$ phase of CSi was retained in the $\mathrm{CSi}-\mathrm{Mg} / \mathrm{TCP} x$ porous ceramics when sintering up to $1180^{\circ} \mathrm{C}$. It suggests that the dilute $\mathrm{Mg}$ doping can stabilize the $\beta$ phase of CSi. Also, there was no $\beta$-to- $\alpha$ transformation for the TCP in the composites because this phase conversion usually takes place at over $1200^{\circ} \mathrm{C}$.

\subsection{Effect of TCP content and sintering temperature on mechanical properties}

The mechanical strength of the bioceramic scaffolds with varying TCP content (0\%-30\%) and sintering temperature $\left(1120-1180^{\circ} \mathrm{C}\right)$ was shown in Figure 2. The compressive strength of the CSi-Mg/TCP $x$ scaffolds $\left(1120^{\circ} \mathrm{C}\right)$ decreased with increasing TCP content, but their porosity varied contrarily. When sintering at $1150^{\circ} \mathrm{C}$, the CSi-Mg/TCP $x(x=0,10,20)$ showed appreciable porosity $(>50 \%)$ and higher strength $(\sim 100-122 \mathrm{MPa})$ than those sintered at a lower $\left(1120^{\circ} \mathrm{C}\right)$ or higher $\left(1180^{\circ} \mathrm{C}\right)$ temperature, but their strength was decreased slowly with increasing TCP content. Until the temperature increasing up to $1180^{\circ} \mathrm{C}$, the $\mathrm{CSi}-\mathrm{Mg} / \mathrm{TCP} 30$ showed an appreciable strength which was approximately 3-8 times higher than those sintered at $1120^{\circ} \mathrm{C}$ and $1150^{\circ} \mathrm{C}$. Although this exceptional strength $(\sim 85 \mathrm{MPa})$ is possibly attributed to sacrificing the porosity of bioceramics (from over $60 \%$ for CSi$\mathrm{Mg} / \mathrm{TCP} 20$ to $~ 50 \%$ for $\mathrm{CSi}-\mathrm{Mg} / \mathrm{TCP} 30)$, indeed this value is $8-10$ times higher than the strength $(<10 \mathrm{MPa})$ for the other CSi and $\mathrm{CaP}$ scaffolds with comparable porosity which were fabricated by the conventional polymer coating or 
infiltration techniques [21]. These results suggest that $\beta$-TCP may affect adversely the sintering property of CSi-Mg substrate, but the composite scaffolds with high content of $\beta$-TCP ( $\geq 20 \%)$ would be endowed with appreciable strength when the sintering temperature is high enough. Moreover, it seems reasonable that, at an appropriate sintering temperature (e.g. $\left.1150^{\circ} \mathrm{C}\right)$, the $\mathrm{CSi}-\mathrm{Mg} / \mathrm{TCP} x(x=10,20)$ scaffolds still displayed high strength $(>80 \mathrm{MPa})$. On the other hand, the scaffold shrinkage was related to the sintering temperature and TCP content, and thus directly related to their strength. It is found that all of porous bioceramics $\left(1180^{\circ} \mathrm{C}\right)$ showed high shrinkage $(\sim 28 \pm 1.5 \%)$, but in comparison the CSi-Mg/TCP30 $\left(1120^{\circ} \mathrm{C}\right)$ showed only $11.5 \%$ shrinkage (see Tab. S1). This dimension changes is in contrast with the unidirectional pore structure in the $3 \mathrm{D}$ printed $\mathrm{BG}$ scaffolds, in which the low BG content in writing ink and small filament diameter $(\sim 100 \mu \mathrm{m})$ inevitably resulted in significant pore shrinkage, and thus contributed to the strong strength parallel to the pore orientation [16].

SEM micrographs of the pore struts highlighted the multi-scale microstructures in the bioceramic scaffolds sintered at $1120-1180^{\circ} \mathrm{C}$ (Fig. 3). The fracture surface of porous bioceramics showed no evidence of bubble defects in the sintered filaments. In comparison with the CSi-Mg/TCP $x(x=0,10)$ scaffolds sintered at $1150^{\circ} \mathrm{C}$, a higher sintering temperature $\left(1180^{\circ} \mathrm{C}\right)$ led to some degree of grain growth in the pore wall of the scaffolds. This structural change is potentially suboptimal for the mechanical resistance of the bioceramic struts. As for the CSi-Mg/TCP20 $\left(1120^{\circ} \mathrm{C}\right)$ and $\mathrm{CSi}-\mathrm{Mg} / \mathrm{TCP} 30\left(1120^{\circ} \mathrm{C}, 1150^{\circ} \mathrm{C}\right)$, the SEM images show that the grains were loosely bonded each other with similar size to the original particles prior to printing, which implies an undersintering characteristic and thus reflects their low strength nature (Fig. 2). In comparison, the $\mathrm{CSi}-\mathrm{Mg} / \mathrm{TCP} 20\left(1150^{\circ} \mathrm{C}, 1180^{\circ} \mathrm{C}\right)$ and $\mathrm{CSi}-$ $\mathrm{Mg} / \mathrm{TCP} 30\left(1180^{\circ} \mathrm{C}\right)$ showed a denser microstructure in the pore struts, thus resulting in the appreciable strengths (>80 MPa). It is reasonable to consider that, the more is $\beta$-TCP content in the bioceramic inks, the higher sintering temperature is required to reach a full densification and appreciable strength.

\subsection{Effect of pore size on the mechanical strength}

Since increased open porosity and pore size facilitate bone ingrowth, a further evaluation involving the pore parameters on the mechanical strength is needed to investigate. As expected, both the top- and side-view pores of the CSi-Mg/TCP $x$ scaffolds with different primary pore sizes (small-pore: $\sim 220 \times 220 \mu \mathrm{m}$; medium-pore: $\sim 320 \times 320 \mu \mathrm{m}$ and large-pore $\sim 480 \times 480 \mu \mathrm{m}$; see Fig. S2 and S3, SI) were maintained with satisfactory dimension when sintering at 
$1150^{\circ} \mathrm{C}$, which would benefit osteoblast ingrowth, nutrient delivery, and vascularization in vivo [22].

Figure 4 showed their porosity and compressive strength after sintering. The small-pore, medium-pore, or largepore $\mathrm{CSi}-\mathrm{Mg} / \mathrm{TCP} x(x=0,10,20)$ scaffolds kept different but stable open porosity $(\sim 41 \%, \sim 52 \%$ and $\sim 58 \%)$, independent of TCP content. Also, these different porosities responded to significantly different strength in compression. It is valuable to be mentioned that the medium-pore scaffolds with $\leq 20 \% \beta$-TCP displayed high strength (>100 MPa) while the porosity was $\sim 51-53 \%$. Interestingly, addition of TCP is helpful to enhance the strength of large-pore scaffolds from $\sim 51.2 \pm 2.1 \mathrm{MPa}$ for $\mathrm{CSi}-\mathrm{Mg} / \mathrm{TCP} 0$ to $87.6 \pm 8.5 \mathrm{MPa}$ for $\mathrm{CSi}-\mathrm{Mg} / \mathrm{TCP} 20$. Nevertheless, high TCP content (30\%) would heavily sacrifice the scaffold's strength even though the pore dimension was only $\sim 220 \times 220 \mu \mathrm{m}$. These investigations suggest that the pore size (or porosity) of the CSi-Mg-based ceramic scaffolds is another important factor to influence its mechanical properties.

\subsection{Effect of heat schedule on the mechanical strength}

Sintering, as an important treatment stage in ceramics processing, has also undergone significant modifications and some novel sintering technologies and routes have been widely introduced. For example, using pressure sintering such as hot (isostatic) pressure and spark plasma sintering are reported as successful approaches to control Caphosphate or Ca-silicate grain growth during extremely high rates of heating process [23-25]. However, the application of pressure and also high rates of heating would need special equipment, and it is particularly disadvantageous for pore maintenance in ceramic scaffolds. TSS method has been widely reported to control the grain growth of modern (bio)ceramics during final-stage sintering process [26]. The sintering under different TSS regimes may be used to investigate the effect of sintering parameters on the densification behavior and grain growth suppression, which eventually contribute to the enhancement of mechanical strength [27, 28]. In this study, we also used two-step sintering as new heating schedule to investigate the mechanical properties of the medium-pore bioceramic scaffolds (Tab. 2).

Figure 5 shows the compressive strength of the bioceramic scaffolds after undergoing different sintering condition, and the changes of compressive strength exhibited the same trend with the elastic modulus (Tab. S2, SI). Data from the compression test revealed that, after holding at $1120-1180^{\circ} \mathrm{C}$ only for $15 \mathrm{~min}$ (Fig. $\left.5 \mathrm{~A}\right)$, the CSi-Mg/TCP $x(x=0$, 10) scaffolds had significantly high strength ( $~ 88-180 \mathrm{MPa})$, which was $2 \sim 10$ times higher than the CSi-Mg/TCP $x$ ( $x$ 
$=20,30$ ), probably due to the undersintering for the later. The fracture surface microstructures of the scaffolds were shown in Figure S4, SI. If the first holding time was prolonged to $45 \mathrm{~min}$ (Fig. 5B), the CSi-Mg/TCP $x(x=20,30)$ sintered at $1180^{\circ} \mathrm{C}$ displayed a significant enhancement in strength (47-76 MPa). These data suggest that TSS is totally favorable for the low-TCP composite scaffolds. That is, therefore, the OSS method is good for the CSi$\operatorname{Mg} / \mathrm{TCP} x(x=20,30)$ scaffolds but the TSS is more adapt for the CSi-Mg/TCP $x(x=0,10)$ scaffolds.

Chen and Wang [29] have explained details of TSS mechanism and its contribution on the microstructure of sintered ceramics. They suggest that to achieve densification without a significant grain growth, grain boundary diffusion needs to remain active, while the grain boundary migration is to be suppressed. A mechanism to slow down the grain boundary movement is the triple-point drag. In our study, the SEM observation is employed to confirm the TSS readily suppresses the bioceramic grain growth and enhances the densification of pore struts in low-TCP composites (Fig. 6). However, the CSi-Mg/TCP20 and CSi-Mg/TCP30 scaffolds treated by two-step sintering all showed an undersintering, and thus small open pores were retained and the fracture struts displayed a low degree of densification in the bioceramics, implying TSS is an efficient approach to control the grain growth but inefficient to improve the densification and mechanical strength of the 3D printed, TCP-rich, $\mathrm{CSi}-\mathrm{Mg} / \mathrm{TCP} x$ ceramics. Totally, the compressive strengths of the CSi-Mg/TCP $x$ scaffolds undergoing OSS or TSS sintering were significantly higher than other bioceramic scaffolds fabricated by similar AMMs [30-45] (Fig. 7). Thus, this finding provides a new strategy that the biphasic hybrid of $\mathrm{CSi}-\mathrm{Mg}$ and $\beta$-TCP is beneficial in fabricating mechanically strong porous bioceramics.

\subsection{Degradation behavior of the scaffolds in vitro}

Biodegradable scaffolds provide the initial structure and stability for tissue formation, but degrade as the tissue forms, providing room for matrix deposition and tissue growth [46]. To further understand the decay in strength and especially the influence of $\beta$-TCP content on that, the CSi-Mg/TCP $x$ were kept in Tris buffer up to 6 weeks (Fig. 8A). The CSi-Mg/TCP $x(x=0,10)$ scaffolds were underwent TSS treatment with the highest initial compressive strength (120-180 MPa), while the CSi-Mg/TCP $x(x=20,30)$ scaffolds with appreciable initial strength ( $\sim 85 \mathrm{MPa})$ were sintered with OSS method. In general, the compressive strength and weight of bioceramic scaffolds are affected by two different mechanisms: (i) the degradation or dissolution effect lead to the loss of strength because of the increase 
in porosity and weakened grain boundaries, and (ii) apatite formation which fills the pores and increases the density and strength of the material. Therefore, the final weight and strength will depend on which one of these mechanisms is the dominant one. Figure $8 \mathrm{~B}$ shows the change in weight as a function of immersion time. The weight of all CSi$\mathrm{Mg} / \mathrm{TCP} x$ scaffolds reduced to $87.0 \sim 91.5 \%$ within the initial 2 weeks, but the $\beta$-TCP scaffolds changed little and remained up to $97 \%$ after 6 weeks. In comparison with the pure CSi-Mg (i.e. CSi-Mg/TCP0) scaffolds, the weight loss of the CSi-Mg/TCP30 was less $3.76 \%$ after 6 weeks, but that for the pure $\beta$-TCP was $14.21 \%$ after 6 weeks.

Figure $8 \mathrm{C}$ shows the $\mathrm{pH}$ changes in the buffers during the immersion stage. It is seen that the $\mathrm{pH}$ value in Tris buffer maintained stable when immersing the pure $\beta$-TCP scaffolds due to the minimal $\beta$-TCP dissolution and ion exchange within 6 weeks. In contrast, the dissolution of CSi-Mg-based scaffolds led to a slow increase in pH value, probably due to the chelation effect of silicate group $\left(\mathrm{SiO}_{4}{ }^{4-}\right)$ with $\mathrm{H}^{+}$during $\mathrm{CSi}-\mathrm{Mg}$ dissolution. Shen et al. have reported that the weak alkaline microenvironment could enhance osteoblast viability and proliferation [47]. However, the over-alkalization in the cell growth medium led by inorganic ion release from bioactive glasses usually result in cell apoptotic in vitro [48]. Thus, the limited increase in $\mathrm{pH}$ value could be thought to be favorable for osteogenic cell growth in the CSi-Mg/TCP $x$ porous constructs.

As for the strength decay during this process, the compressive strength of CSi-Mg/TCP0 scaffolds decreased nearly a half within 2 weeks, from $\sim 180 \mathrm{MPa}$ to $\sim 83 \mathrm{MPa}$, and then maintained a very slow reduction. The CSi$\operatorname{Mg} / \mathrm{TCP} x(x=10,20,30)$ scaffolds changed slowly with appreciable compressive strength (51 54 MPa) during the whole immersion stage of 6 weeks, and these values were over 8 times higher than the pure $\beta$-TCP scaffolds (Fig. 8D). Overall, all the composite scaffolds showed the same trend that compressive strength decreased continuously as a function of time. Their strength remained almost the same tendency over 6 weeks, and the CSi-Mg/TCP10 scaffolds showed the largest compressive strength (54 MPa). Interestingly, although the initial elastic modulus was decreased with the increase of $\beta$-TCP content, the composite scaffolds maintained higher values than the pure CSi$\mathrm{Mg}$ and $\beta$-TCP scaffolds after immersion for 6 weeks (Fig. 8E). This can be also confirmed by the representative stress-strain curves for the samples during compression test (Fig. 8F). It implies that the $\beta$-TCP-added CSi-Mg/TCP $x$ composite scaffolds possess higher compressive endurance. It is reasonable to conclude that, therefore, the CSi$\mathrm{Mg} / \mathrm{TCP} x$ composite scaffolds show a good mechanical stability in aqueous medium with physiological pH condition, 
which would be adapt for the large segmental bone defect applications.

Figure 9 shows the changes in ion concentrations in Tris buffers during immersing the porous samples. The Ca, $\mathrm{Mg}$ and Si concentrations were increased with immersion time, while the P concentration rapidly increased initially and then decreased, except for the pure $\beta$-TCP. According to the changes in surface SEM observation and $\mathrm{Ca} / \mathrm{P}$ ratio analysis for the as-immersed samples (see Fig. S5, SI), it might be assumed that a new Ca-phosphate layer was deposited on the surface of the pore struts of Ca-silicate-based scaffolds. In general, the decay in strength of the bioceramics during immersion in Tris buffer is different with that during immersion in simulated body fluids (SBF) $[19,49]$.The formation of biomimetic apatite layer in (simulated) body fluid has been reported to be responsible for the strong bonding between bioceramics and host bone tissue [50]. The deposition of the apatite layer is usually considered an indication of good bioactivity in vitro. The bioceramic dissolution leads to a significant decrease in weight but new apatite layer resulted in mechanical stability. This performance parameter is favorable for bone tissue regeneration in the early stage. In this regard, it is reasonable to consider that a biomimetic apatite layer can readily deposit on the surface of the pore struts in such composite scaffolds when immersing in SBF.

\section{Conclusions}

In summary, we have proven our hypothesis that addition of $\beta$-TCP can readily balance the properties of the fully interconnected porous bioceramic constructs significantly, such as highly balanced strength, low dependence of $\beta$ TCP and sintering temperature, and the ability to maintain adjusted degradation. The hybrid porous bioceramic reliably preserved these mechanical properties in buffer solution, and it also exhibited appropriate mechanical flexibility. We believe this approach presents a promising strategy for developing biodegradation-adjustable, high strength bioceramic scaffolds, indicating substantial promise of bone defect repair applications-for example, in in situ thin-wall skull or load-bearing segmental bone regeneration and repair.

\section{Acknowledgments}

This work was supported by the Zhejiang Provincial Natural Science Foundation of China (LZ14E020001, LQ14H060003), and the Science Fund for Creative Research Groups of National Natural Science Foundation of China (51221004), National Science Foundation of China (51372218, 51375440, 81271956), and the Science and Technology Department of Zhejiang Province Foundation (2014C33202,2015C33119). 


\section{References}

[1] Perka C, Schultz O, Spitzer RS, Lindenhayn K, Burmester GR, Sittinger M. Segmental bone repair by tissueengineered periosteal cell transplants with bioresorbable fleece and fibrin scaffolds in rabbits. Biomaterials 2000; $21(11):$ 1145-53.

[2] Komaki H, Tanaka T, Chazono M, Kikuchi T. Repair of segmental bone defects in rabbit tibiae using a complex of beta-tricalcium phosphate, type I collagen, and fibroblast growth factor-2. Biomaterials 2006; 27(29): 511826.

[3] Gugala Z, Gogolewski S. Healing of critical-size segmental bone defects in the sheep tibiae using bioresorbable polylactide membranes. Injury 2002; 33: 71-6.

[4] Kansal I, Goel A, Tulyaganov DU, Pascual MJ, Lee HY, Kim HW, et al. Diopside $\left(\mathrm{CaOMgO}_{2} \mathrm{SiO}_{2}\right)$-fluorapatite $\left(9 \mathrm{CaO}_{3} \mathrm{P}_{2} \mathrm{O}_{5} \mathrm{CaF}_{2}\right)$ glass-ceramics: potential materials for bone tissue engineering. J Mater Chem 2011; 21: 16247-56.

[5] Reichert JC, Saifzadeh S, Wullschleger ME, Epari DR, Schütz MA, Duda GN, et al. The challenge of establishing preclinical models for segmental bone defect research. Biomaterials 2009; 30(12): 2149-63.

[6] Mayr HO, Klehm J, Schwan S, Hube R, Südkamp NP, Niemeyer P, et al. Microporous calcium phosphate ceramics as tissue engineering scaffolds for the repair of osteochondral defects: biomechanical results. Acta Biomater 2013; 9(1): 4845-55.

[7] Bose S, Roy M, Bandyopadhyay A. Recent advances in bone tissue engineering scaffolds. Trends Biotechnol 2012; 30(10): 546-54.

[8] Hutmacher DW. Scaffolds in tissue engineering bone and cartilage. Biomaterials 2000; 21(24): 2529-43.

[9] Wu C, Chang J. A review of bioactive silicate ceramics. Biomed Mater 2013; 8(3): 032001.

[10] Liu X, Ding C. Phase compositions and microstructure of plasma sprayed wollastonite coating. Surf Coating Technol 2002; 141(23): 269-74.

[11] Xie J, Yang X, Shao H, Ye J, He Y, Fu J, et al. Simultaneous mechanical property and biodegradation improvement of wollastonite bioceramic through magnesium dilute doping. J Mech Behav Biomed 2016; 54: 60-71. 
[12] Miranda P, Saiz E, Gryn K, Tomsia AP. Sintering and robocasting of beta-tricalcium phosphate scaffolds for orthopaedic applications. Acta Biomater 2006; 2: 457-66.

[13] Wu C, Fan W, Zhou Y, Luo Y, Gelinsky M, Chang J, et al. 3D-printing of highly uniform $\mathrm{CaSiO}_{3}$ ceramic scaffolds: preparation, characterization and in vivo osteogenesis. J Mater Chem 2012; 22: 12288-95.

[14] Schlordt T, Schwanke S, Keppner F, Fey T, Travitzky N, Greil P. Robocasting of alumina hollow filament lattice structures. J Eur Ceram Soc 2013; 33(15): 3243-8.

[15] Eqtesadi S, Motealleh A, Pajares A, Guiberteau F, Miranda P. Influence of sintering temperature on the mechanical properties of $\epsilon$-PCL-impregnated 45S5 bioglass-derived scaffolds fabricated by robocasting. $J$ Eur Ceram Soc 2015; 35(14): 3985-93.

[16] Fu Q, Saiz E, Tomsia P. Bioinspired strong and highly porous glass scaffolds. Adv Funct Mater 2011; 21: 105863.

[17] Oryan A, Alidadi S, Moshiri A, Maffulli N. Bone regenerative medicine: classic options, novel strategies, and future directions. J Orthop Surg Res 2014; 9: 18-42.

[18] Xu S, Lin K, Wang Z, Chang J, Wang L, Lu J, et al. Reconstruction of calvarial defect of rabbits using porous calcium silicate bioactive ceramics. Biomaterials 2008; 29: 2588-96.

[19] Shao H, Yang X, He Y, Fu J, Liu L, Ma L, et al. Bioactive glass-reinforced bioceramic ink writing scaffolds: sintering, microstructure and mechanical behavior. Biofabrication 2015; 7: 035010.

[20] Ma J, Chen CZ, Wang DG, Meng XG, Shi J L. Influence of the sintering temperature on the structural feature and bioactivity of sol-gel derived $\mathrm{SiO}_{2}-\mathrm{CaO}-\mathrm{P}_{2} \mathrm{O}_{5}$ bioglass. Ceram Int 2010; 36: 1911-6.

[21] Philippart A, Boccaccini AR, Fleck C, Schubert DW, Roether JA. Toughening and functionalization of bioactive ceramic and glass bone scaffolds by biopolymer coatings and infiltration: a review of the last 5 years. Expert Rev Med Devic 2015; 12: 93-111.

[22] Karageorgiou V, Kaplan D. Porosity of 3D biomaterial scaffolds and osteogenesis. Biomaterials 2005; 26: 547491.

[23] Gu YW, Loh NH, Khor KA, Tor SB, Cheang P. Spark plasma sintering of hydroxyapatite powders. Biomaterials 
2002; 23(1): 37-43.

[24] Champion E. Sintering of calcium phosphate bioceramics. Acta Biomater 2013; 9: 5855-75.

[25] Guo X, Xiao P, Liu J, Shen Z. Fabrication of nanostructured hydroxyapatite via hydrothermal synthesis and spark plasma sintering. J Am Ceram Soc 2005; 88(4): 1026-9.

[26] Mazaheri M, Zahedi A M, Sadrnezhaad S K. Two-step sintering of nanocrystalline ZnO compacts: Effect of temperature on densification and grain growth. J Am Ceram Soc 2008; 91(1): 56-63.

[27] Nadernezhad A, Moztarzadeh F, Hafezi M, Barzegar-Bafrooei H. Two step sintering of a novel calcium magnesium silicate bioceramic: Sintering parameters and mechanical characterization. J Eur Ceram Soc 2014; 34(15): 4001-9.

[28] Lukić M, Stojanović Z, Škapin SD, Maček-Kržmanc M, Mitrić M, Marković S, et al. Dense fine-grained biphasic calcium phosphate (BCP) bioceramics designed by two-step sintering. J Eur Ceram Soc 2011; 31(1): $19-27$.

[29] Chen I-W, Wang X-H. Sintering dense nanocrystalline ceramics without final-stage grain growth. Nature 2000; 404: $168-71$.

[30] Vivanco J, Aiyangar A, Araneda A, Ploeg H-L. Mechanical characterization of injection-molded macro porous bioceramic bone scaffolds. J Mech Behav Biomed 2012; 9: 137-52.

[31] Feng P, Wei P, Shuai C, Peng S. Characterization of mechanical and biological properties of 3-D scaffolds reinforced with zinc oxide for bone tissue engineering. PloS One 2014; 9: e87755.

[32] Fielding GA, Bandyopadhyay A, Bose S. Effects of silica and zinc oxide doping on mechanical and biological properties of 3D printed tricalcium phosphate tissue engineering scaffolds. Dent Mater 2012; 28(2): 113-22.

[33] Tarafder S, Balla VK, Davies NM, Bandyopadhyay A, Bose S. Microwave sintered 3D printed tricalcium phosphate scaffolds for bone tissue engineering. J Tissue Eng Regen Med 2013; 7(8): 631-41.

[34] Liu D, Zhuang J, Shuai C, Peng S. Mechanical properties' improvement of a tricalcium phosphate scaffold with poly-l-lactic acid in selective laser sintering. Biofabrication 2013; 5: 025005. 
[35] Shuai C, Gao C, Feng P, Peng S. Graphene-reinforced mechanical properties of calcium silicate scaffolds by laser sintering. RSC Adv 2014; 4: 12782-8.

[36] Shuai C, Mao Z, Han Z, Peng S. Preparation of complex porous scaffolds via selective laser sintering of poly (vinyl alcohol)/calcium silicate. J Bioact Compat Pol 2014; 29(2): 110-20.

[37] Shuai C, Mao Z, Han Z, Peng S, Li Z. Fabrication and characterization of calcium silicate scaffolds for tissue engineering. J Mech Med Biol 2014; 14(04): 1450049.

[38] Han Z, Feng P, Gao C, Shen Y, Shuai C, Peng S. Microstructure, mechanical properties and in vitro bioactivity of akermanite scaffolds fabricated by laser sintering. Bio-med Mater Eng 2014; 24(6): 2073-80.

[39] Feng P, Gao C, Shuai C, Peng S. Liquid Phase Sintered Ceramic Bone Scaffolds by Combined Laser and Furnace nano-titania. RSC Adv 2015; 5(5): 3498-507.

[40] Woodard JR, Hilldore AJ, Lan SK, Park CJ, Morgan A W, Eurell JAC, et al. The mechanical properties and osteoconductivity of hydroxyapatite bone scaffolds with multi-scale porosity. Biomaterials 2007; 28(1): 45-54.

[41] Feng P, Niu M, Gao C, Peng S, Shuai C. A novel two-step sintering for nano-hydroxyapatite scaffolds for bone tissue engineering. Sci Rep 2014; 4: 5599.

[42] Kolan KCR, Leu MC, Hilmas GE, Brown RF, Velez M. Fabrication of 13-93 bioactive glass scaffolds for bone tissue engineering using indirect selective laser sintering. Biofabrication 2011; 3(2): 025004.

[43] Liu X, Rahaman MN, Hilmas GE, Bal BS. Mechanical properties of bioactive glass (13-93) scaffolds fabricated by robotic deposition for structural bone repair. Acta Biomater 2013; 9(6): 7025-34.

[44] Deliormanlı AM, Rahaman MN. Direct-write assembly of silicate and borate bioactive glass scaffolds for bone repair. J Eur Ceram Soc 2012; 32(14): 3637-46.

[45] Eqtesadi S, Motealleh A, Miranda P, Pajares A, Lemos A, Ferreira JMF. Robocasting of 45S5 bioactive glass scaffolds for bone tissue engineering. J Eur Ceram Soc 2014; 34(1): 107-18. 
[46] Burg KJ, Porter S, Kellam JF. Biomaterial developments for bone tissue engineering. Biomaterials 2000; 21(23): 2347-59.

[47] Shen Y, Liu W, Wen C, Pan H, Wang T, Darvell BW, Lu WW, Huang W. Bone regeneration: importance of local pH-strontium-doped borosilicate scaffolds. J Mater Chem B 2012; 22: 8662-70.

[48] Gough JE, Julian R. Jones JR, Hench LL. Nodule formation and mineralization of human primary osteoblasts cultured on a porous bioactive glass scaffold. Biomaterials 2004; 25: 2039-46.

[49] Bandyopadhyay A, Bernard S, Xue W, Bose S. Calcium Phosphate-Based Resorbable Ceramics: Influence of MgO, ZnO, and SiO2 Dopants. J Am Ceram Soc 2006; 89(9): 2675-88.

[50] Lee J H, Nam H, Ryu H-S, Seo J-H, Chang B-S, Lee C-K. Bioactive ceramic coating of cancellous screws improves the osseointegration in the cancellous bone. J Orthop Sci 2011; 16: 291-7. 


\section{Figure captions}

Figure 1. Primary characterization of the $\mathrm{CSi}-\mathrm{Mg} / \mathrm{TCPx}(\mathrm{x}=0,10,20,30)$ scaffolds after one-step sintering at $1180^{\circ} \mathrm{C}$ for $3 \mathrm{~h}$. (A) Optical images of the scaffolds. (B) $\mu \mathrm{CT}$ reconstructed $3 \mathrm{D}, 2 \mathrm{D}$ images of the scaffolds. (A) XRD patterns of the scaffolds.

Figure 2. Compressive strength and porosity of the medium-pore CSi-Mg/TCPx (x=0, 10, 20, 30) scaffolds after one-step sintering at $1120^{\circ} \mathrm{C}, 1150^{\circ} \mathrm{C}$ and $1180^{\circ} \mathrm{C}$ for $3 \mathrm{~h}$, respectively.

Figure 3. SEM micrographs of the surface microstructure of the pore wall in the medium-pore CSi-Mg/TCP $x$ $(x=0,10,20,30)$ scaffolds after one-step sintering at $1120^{\circ} \mathrm{C}-1180^{\circ} \mathrm{C}$.

Figure 4. Compressive strength and porosity of the CSi-Mg/TCP $x(x=0,10,20,30)$ scaffolds with different pore sizes after one-step sintering at $1150^{\circ} \mathrm{C}$ for $3 \mathrm{~h}$.

Figure 5. Compressive strength and porosity of the medium-pore $\mathrm{CSi}-\mathrm{Mg} / \mathrm{TCP} x$ scaffolds after sintering at different temperatures for $15 \mathrm{~min}(\mathrm{~A})$ and $45 \mathrm{~min}(\mathrm{~B})$, and then kept at $1060^{\circ} \mathrm{C}$ for $3 \mathrm{~h}$.

Figure 6. SEM images of the fracture surface without and with thermal etching of the composite scaffolds after (A) one-step sintering at $1150^{\circ} \mathrm{C}$ for $3 \mathrm{~h}$ and (B) two-step sintering at $1150^{\circ} \mathrm{C}$ for $15 \mathrm{~min}$ and then sintering at $1060^{\circ} \mathrm{C}$ for $3 \mathrm{~h}$.

Figure 7. Compressive strength vs. porosity of the 3D-printed BG (e.g. 45S5 BG, 13-93 BG, 6P53B glass) and bioceramic (e.g. akermanite, wollastonite, HA, $\beta$-TCP, CSi-Mg/TCP) scaffolds with additive manufacturing methods. Each color of pattern corresponds to a different materials; Blue: $\beta$-TCP, Orange: wollastonite, Purple: Akermanite, Dark brown: HA, Yellow: Bioactive glass, and Red: $\mathrm{CSi}-\mathrm{Mg} / \mathrm{TCP}$.

Figure 8. Degradation test in Tris buffer $(\mathrm{pH}=7.4)$ for 6 weeks. (A) Schematic illustration of the scaffolds soaking in the buffer; (B) Changes in weight (\%) of the scaffolds as a function of immersion time; (C) $\mathrm{pH}$ change in buffer; (D) Uniaxial compressive strengths of the scaffolds as a function of time; (E) The Elastic modulus of scaffolds during mechanical testing for 0 week and 6 weeks respectively; (F) The relationship between stress and scaffold strain during mechanical testing for 0 week and 6 weeks respectively. The elastic modulus in (E) was calculated from the slope of the linear segment of the stress-strain curve. The difference of change in weight (\%) between TCP and $\mathrm{CSi}-\mathrm{Mg} / \mathrm{TCP} 0$ was $\sim 14.2 \%$, but that between $\mathrm{CSi}-\mathrm{Mg} / \mathrm{TCP} 30$ and $\mathrm{CSi}-\mathrm{Mg} / \mathrm{TCP} 0$ was only $~ 3.8 \%$ after 6 weeks of immersion in Tris buffer.

Figure 9. Changes of ion concentrations in Tris buffer during immersing the scaffolds for different time stages. 


\section{Figures}

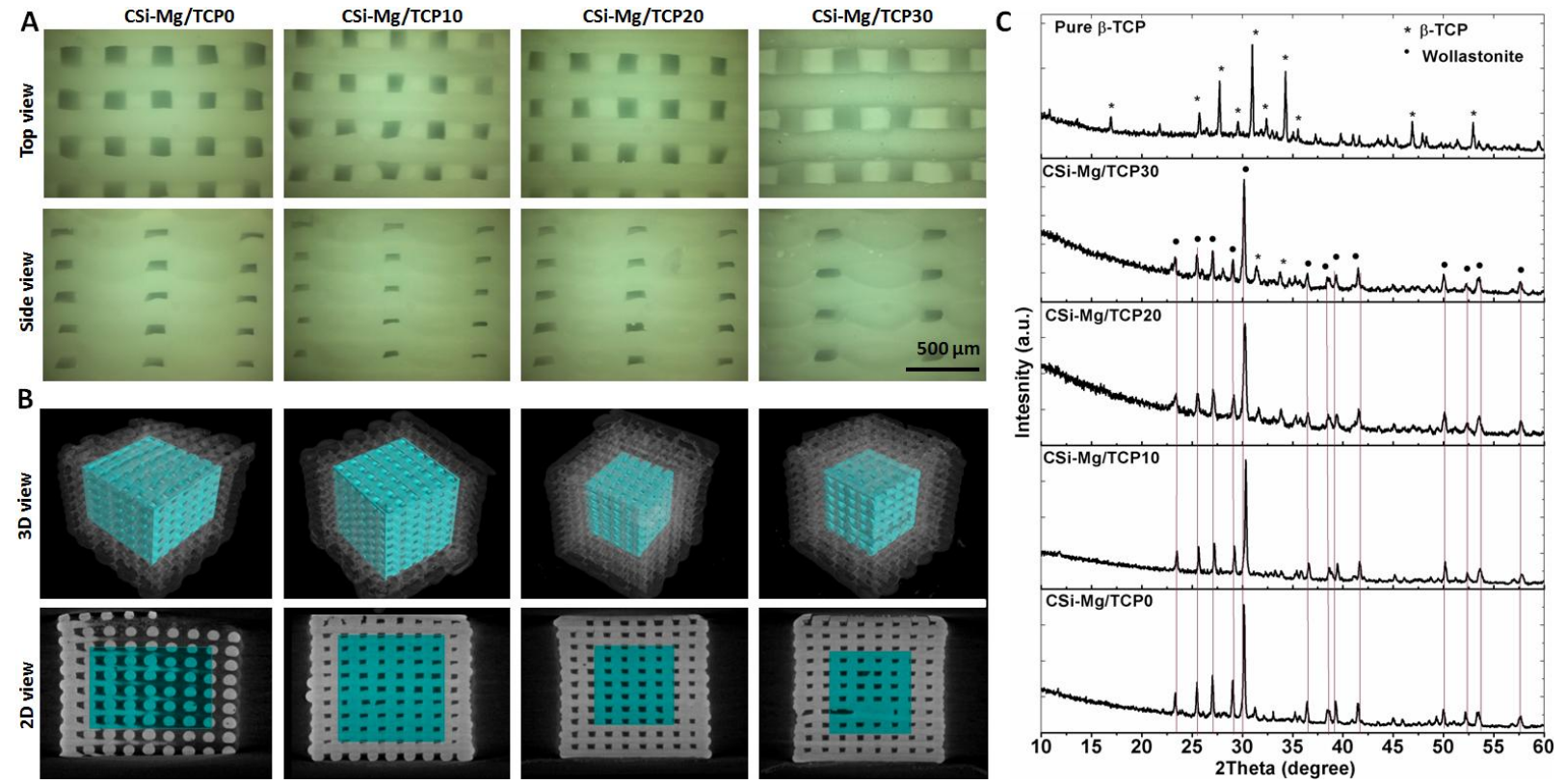

Figure 1. Primary characterization of the $\mathrm{CSi}-\mathrm{Mg} / \mathrm{TCP} x(x=0,10,20,30)$ scaffolds after one-step sintering at $1180^{\circ} \mathrm{C}$ for $3 \mathrm{~h}$. (A) Optical images of the scaffolds. (B) $\mu \mathrm{CT}$ reconstructed 3D, 2D images of the scaffolds. (A) XRD patterns of the scaffolds. 


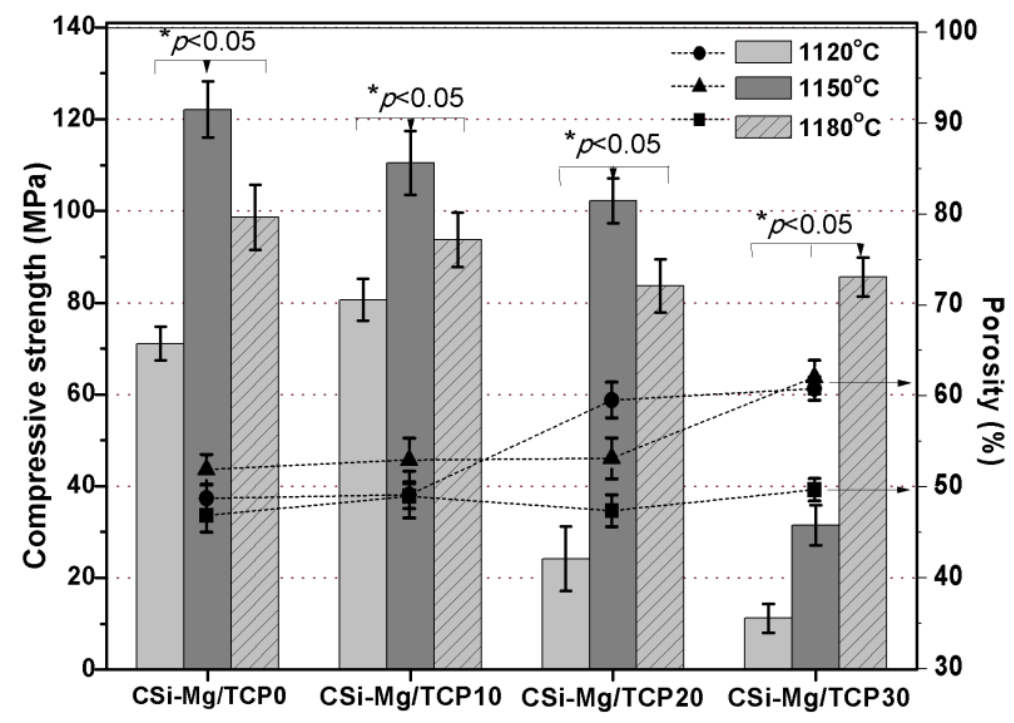

Figure 2. Compressive strength and porosity of the medium-pore $\mathrm{CSi}-\mathrm{Mg} / \mathrm{TCP} x(x=0,10,20,30)$ scaffolds after one-step sintering at $1120^{\circ} \mathrm{C}, 1150^{\circ} \mathrm{C}$ and $1180^{\circ} \mathrm{C}$ for $3 \mathrm{~h}$, respectively. 


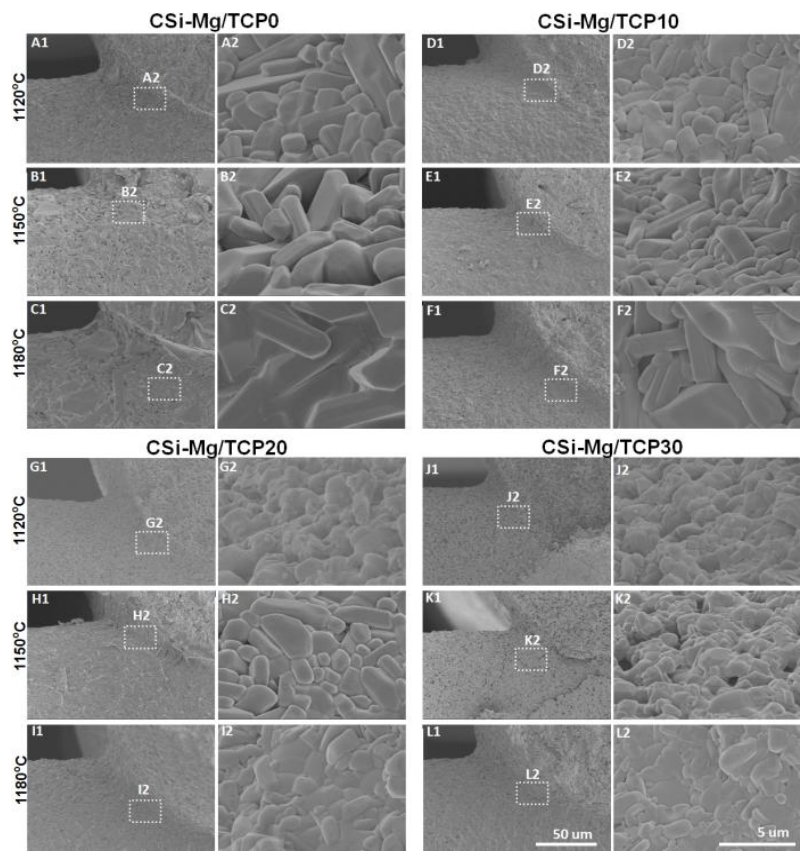

Figure 3. SEM micrographs of the surface microstructure of the pore wall in the medium-pore CSi-Mg/TCP $x$ $(x=0,10,20,30)$ scaffolds after one-step sintering at $1120^{\circ} \mathrm{C}-1180^{\circ} \mathrm{C}$. 


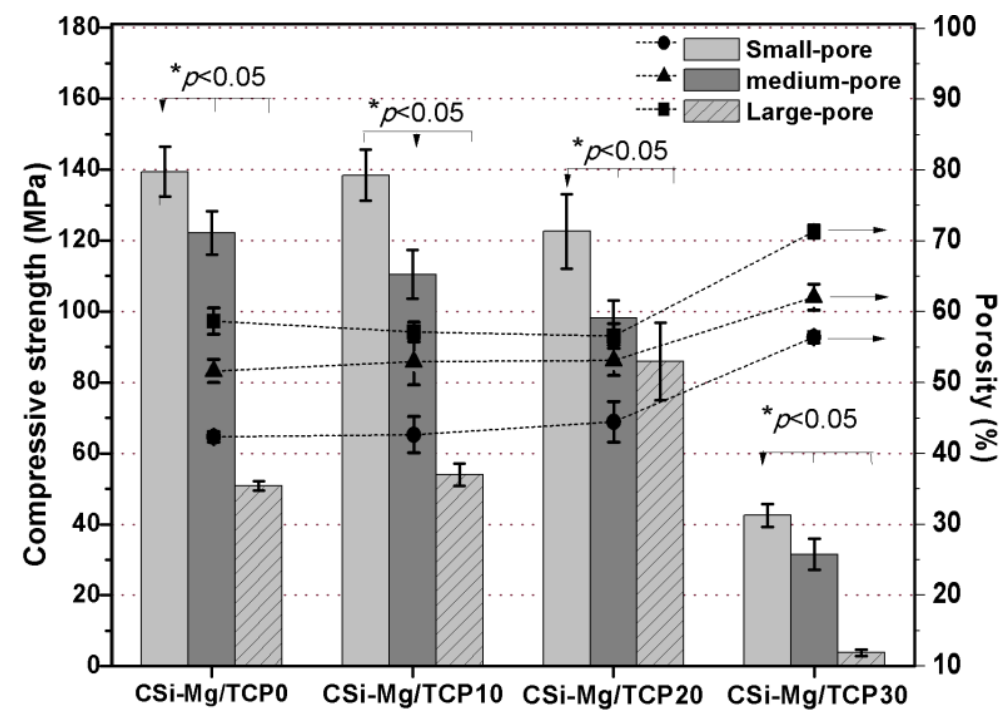

Figure 4. Compressive strength and porosity of the CSi-Mg/TCP $x(x=0,10,20,30)$ scaffolds with different pore sizes after one-step sintering at $1150^{\circ} \mathrm{C}$ for $3 \mathrm{~h}$. 


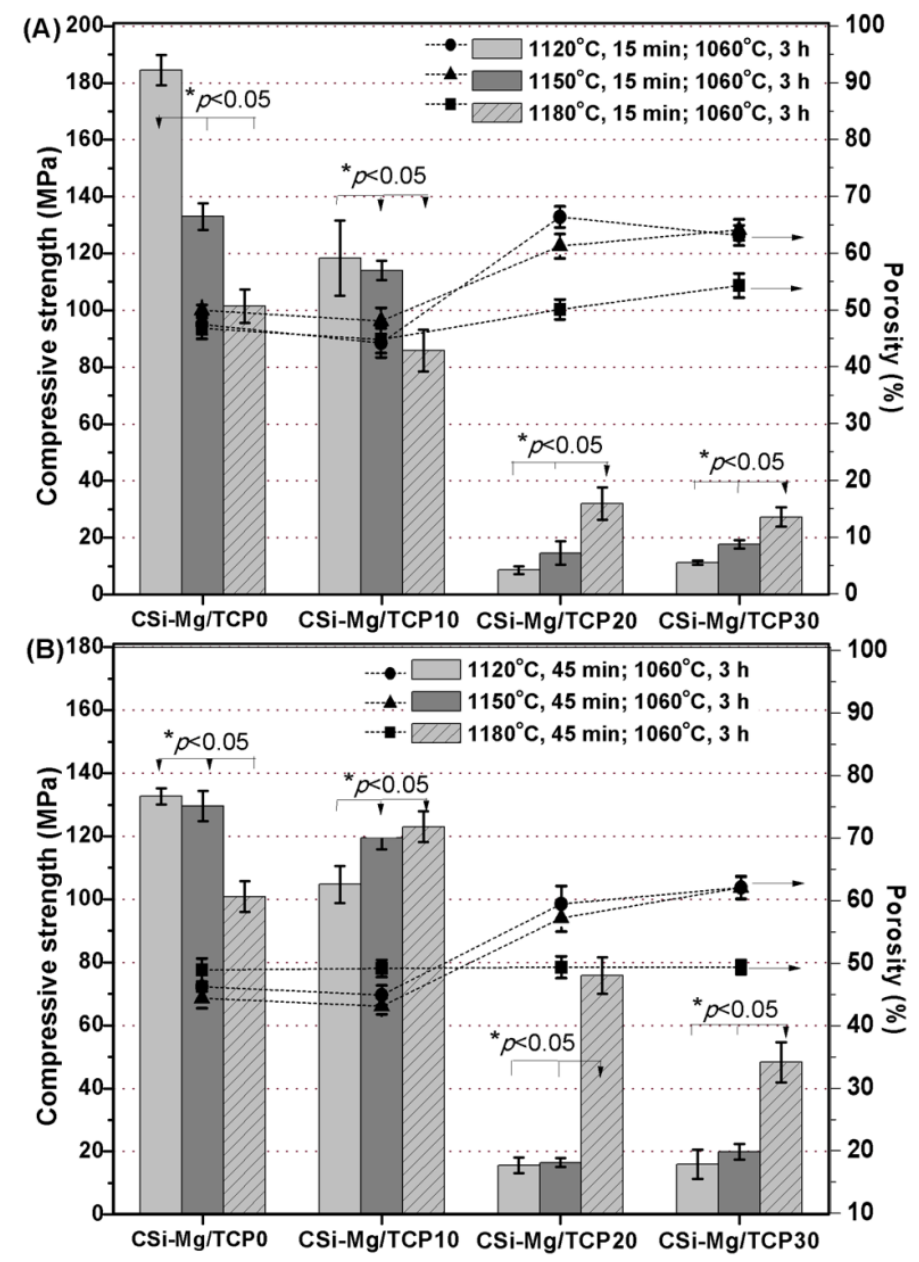

Figure 5. Compressive strength and porosity of the medium-pore CSi-Mg/TCP $x$ scaffolds after sintering at different temperatures for $15 \mathrm{~min}(\mathrm{~A})$ and $45 \mathrm{~min}(\mathrm{~B})$, and then kept at $1060^{\circ} \mathrm{C}$ for $3 \mathrm{~h}$. 

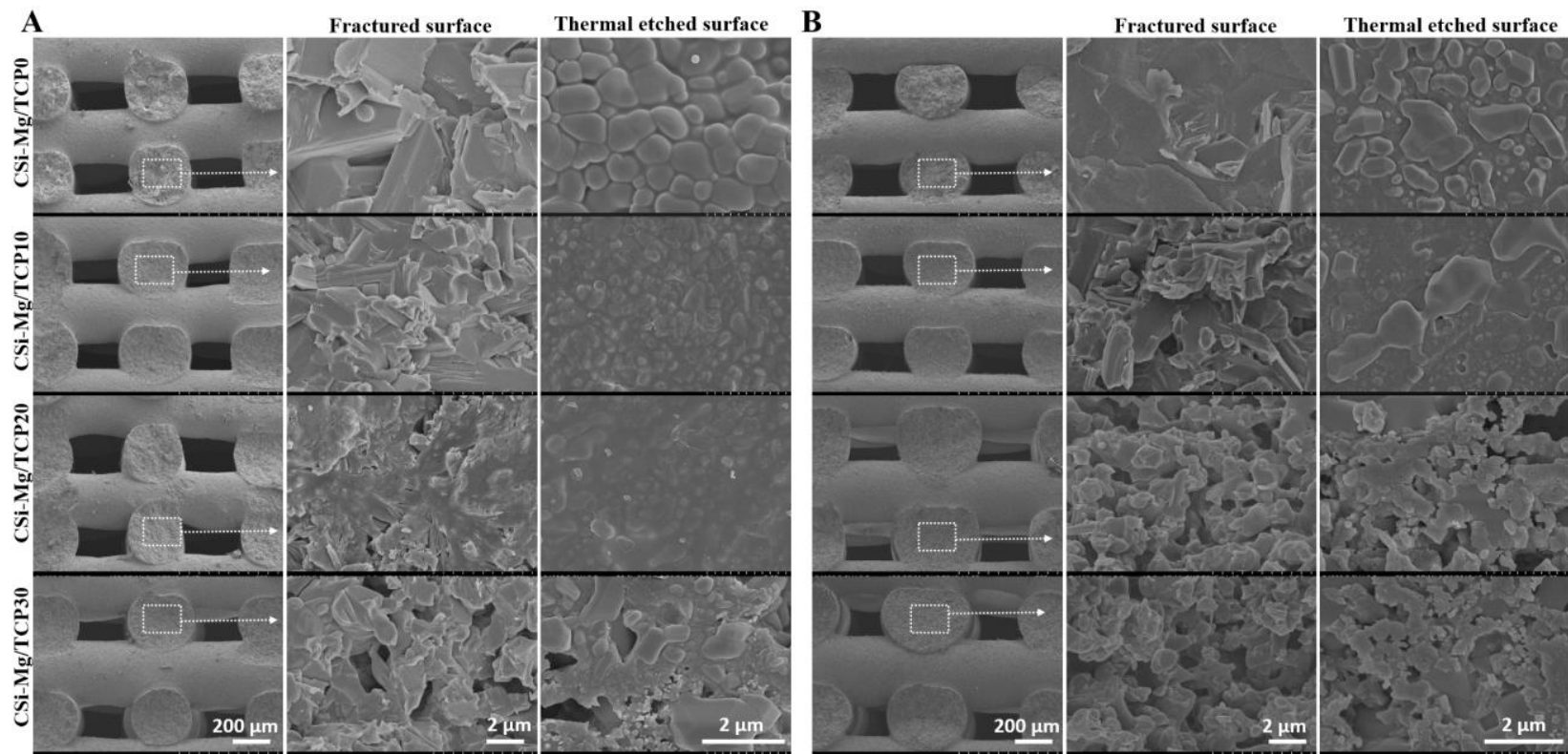

Figure 6. SEM images of the fracture surface without and with thermal etching of the composite scaffolds after (A) one-step sintering at $1150^{\circ} \mathrm{C}$ for $3 \mathrm{~h}$ and (B) two-step sintering at $1150^{\circ} \mathrm{C}$ for $15 \mathrm{~min}$ and then sintering at $1060^{\circ} \mathrm{C}$ for $3 \mathrm{~h}$. 


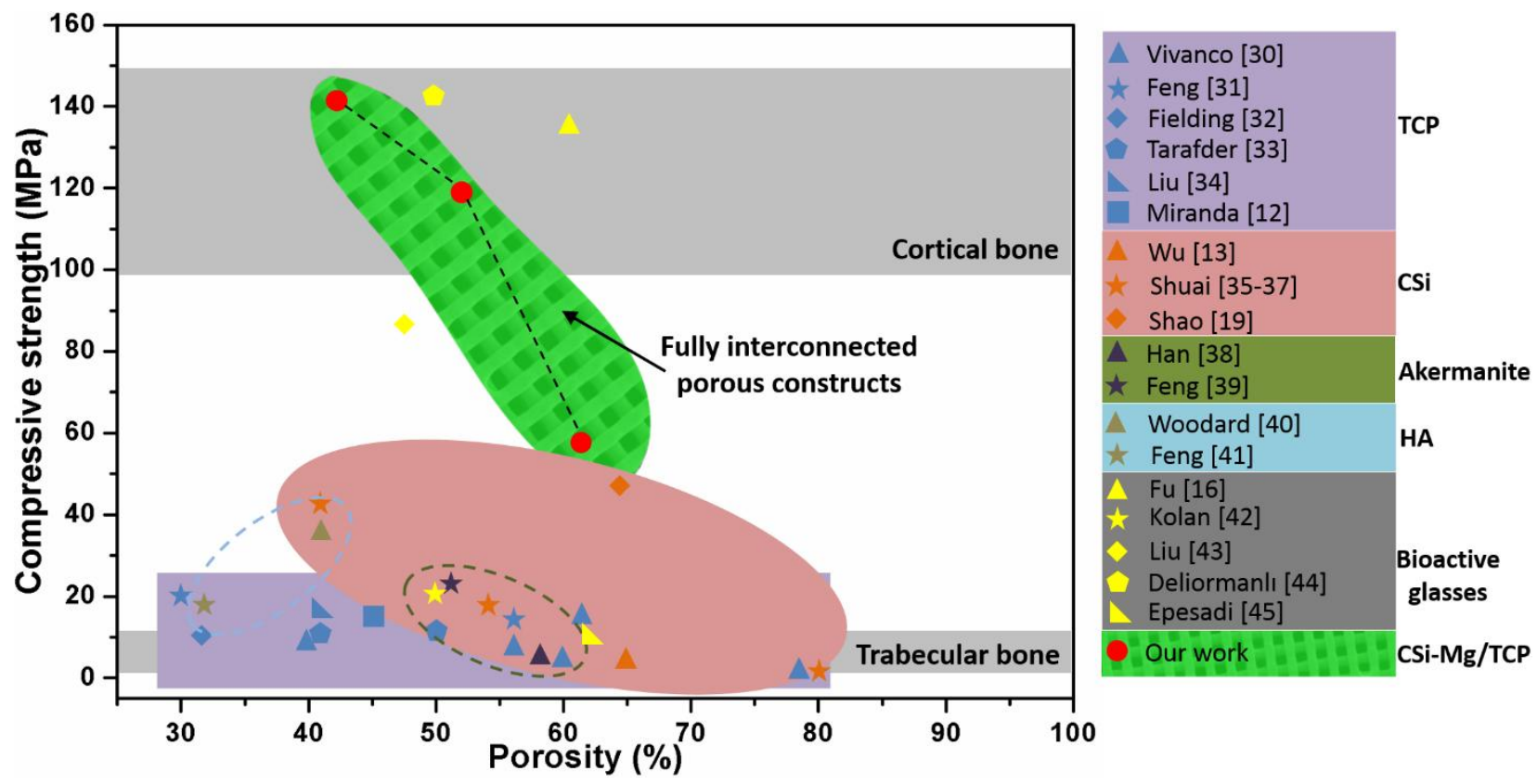

Figure 7. Compressive strength vs. porosity of the 3D-printed BG (e.g. 45S5 BG, 13-93 BG, 6P53B glass) and bioceramic (e.g. akermanite, wollastonite, HA, $\beta$-TCP, CSi-Mg/TCP) scaffolds with additive manufacturing methods. Each color of pattern corresponds to a different materials; Blue: $\beta$-TCP, Orange: wollastonite, Purple: Akermanite, Dark brown: HA, Yellow: Bioactive glass, and Red: $\mathrm{CSi}-\mathrm{Mg} / \mathrm{TCP}$. 

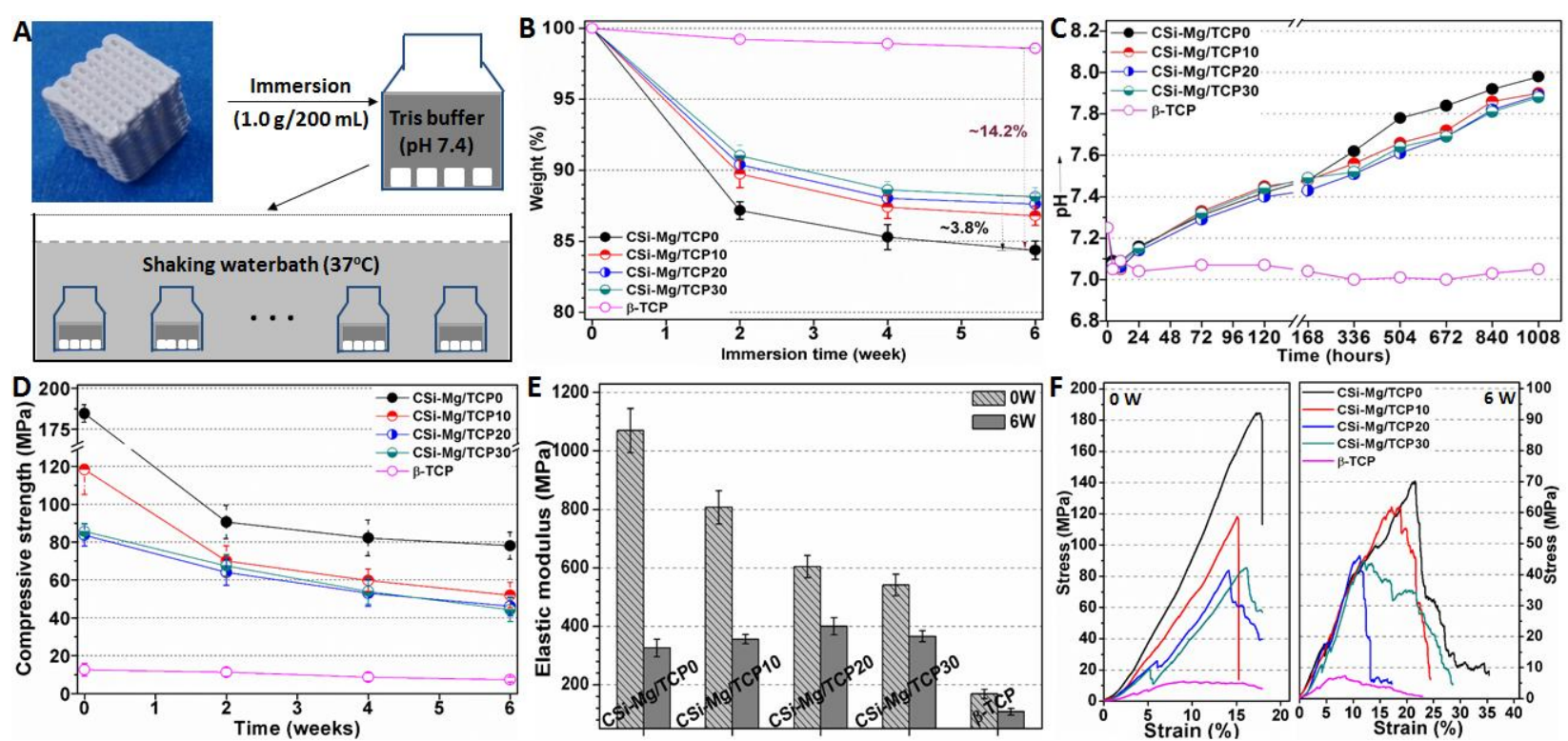

Figure 8. Degradation test in Tris buffer $(\mathrm{pH}=7.4)$ for 6 weeks. (A) Schematic illustration of the scaffolds soaking in the buffer; (B) Changes in weight (\%) of the scaffolds as a function of immersion time; (C) $\mathrm{pH}$ change in buffer; (D) Uniaxial compressive strengths of the scaffolds as a function of time; (E) The Elastic modulus of scaffolds during mechanical testing for 0 week and 6 weeks respectively; $(\mathrm{F})$ The relationship between stress and scaffold strain during mechanical testing for 0 week and 6 weeks respectively. The elastic modulus in (E) was calculated from the slope of the linear segment of the stress-strain curve. The difference of change in weight (\%) between TCP and CSi-Mg/TCP0 was $\sim 14.2 \%$, but that between $\mathrm{CSi}-\mathrm{Mg} / \mathrm{TCP} 30$ and $\mathrm{CSi}-\mathrm{Mg} / \mathrm{TCP} 0$ was only $\sim 3.8 \%$ after 6 weeks of immersion in Tris buffer. 

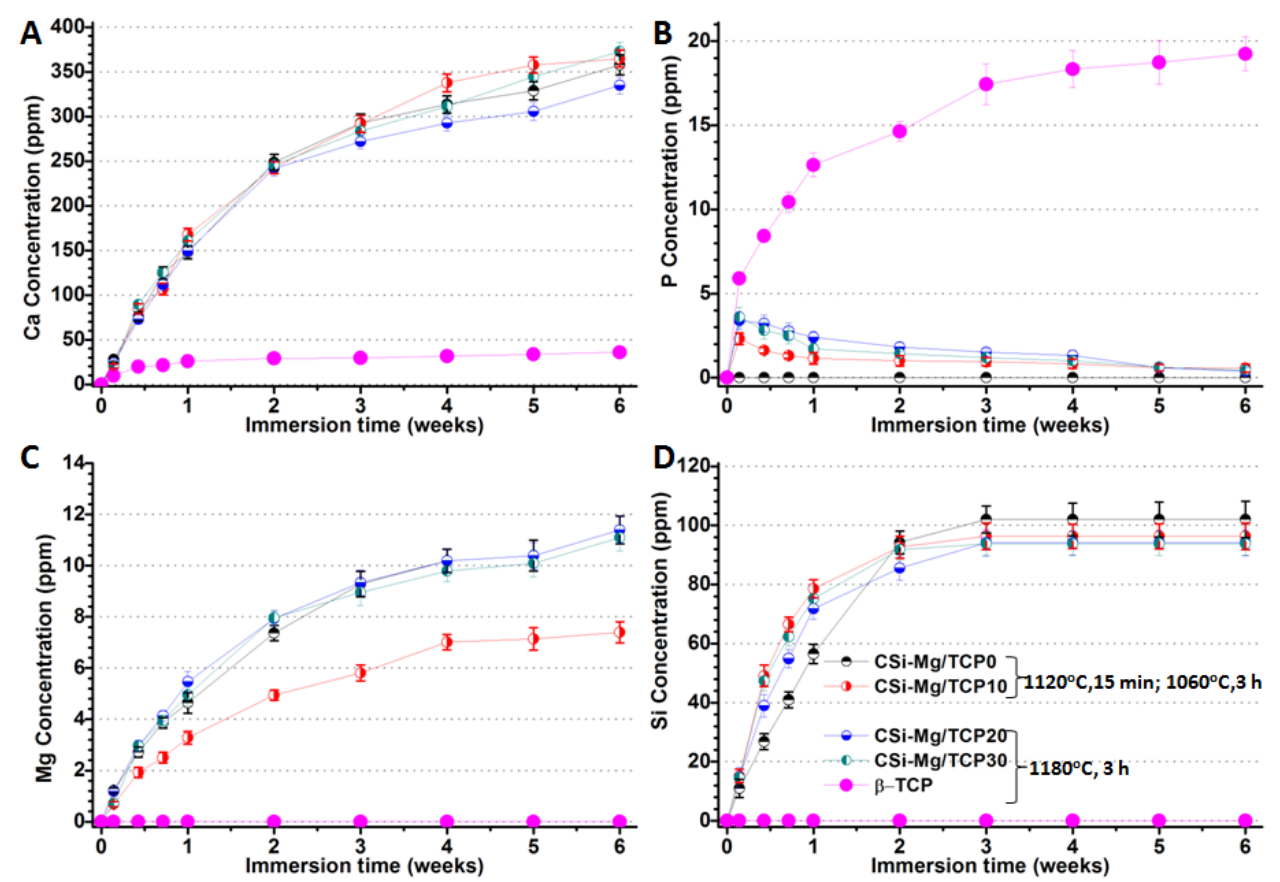

Figure 9. Changes of ion concentrations in Tris buffer during immersing the scaffolds for different time stages. 


\section{Tables}

Table 1. Chemical composition in the ceramic inks.

\begin{tabular}{|c|c|c|c|}
\hline Samples & $\begin{array}{c}\text { CSi-Mg10 } \\
(\mathrm{g})\end{array}$ & $\begin{array}{c}\beta-\mathrm{TCP} \\
(\mathrm{g})\end{array}$ & PVA solution $(6 \% ; \mathrm{g})$ \\
\hline CSi-Mg/TCP0 & 5.40 & 0.00 & 4.0 \\
\hline CSi-Mg/TCP10 & 4.86 & 0.54 & 4.0 \\
\hline $\mathrm{CSi}-\mathrm{Mg} / \mathrm{TCP} 20$ & 4.32 & 1.08 & 4.0 \\
\hline CSi-Mg/TCP30 & 3.78 & 1.62 & 4.0 \\
\hline$\beta$-ТCP & 0.00 & 5.40 & 4.0 \\
\hline
\end{tabular}


Table 2. List of sintering parameters for OSS and TSS regimes.

\begin{tabular}{ccccc}
\hline Heating regime & $\mathrm{T}_{1}\left({ }^{\circ} \mathrm{C}\right)$ & $\mathrm{t}_{1}(\min )$ & $\mathrm{T}_{2}\left({ }^{\circ} \mathrm{C}\right)$ & $\mathrm{t}_{2}(\mathrm{~h})$ \\
\hline OSS & 1120 & 180 & 0 & 0 \\
OSS & 1150 & 180 & 0 & 0 \\
OSS & 1180 & 180 & 0 & 0 \\
TSS1 & 1120 & 15,45 & 1060 & 3 \\
TSS2 & 1150 & 15,45 & 1060 & 3 \\
TSS3 & 1180 & 15,45 & 1060 & 3
\end{tabular}

